\title{
Surface signature of Mediterranean water eddies in the Northeastern Atlantic: effect of the upper ocean stratification
}

\author{
I. Bashmachnikov ${ }^{1}$ and X. Carton ${ }^{2}$ \\ ${ }^{1}$ Institute of Oceanography of the Faculty of Sciences of the University of Lisbon (OI-FCUL), Campo Grande, \\ 1749-016, Lisbon, Portugal \\ ${ }^{2}$ Laboratoire de Physique des Océans, UMR 6523, Université deBretagne Occidentale, 6 avenue Le Gorgeu, \\ 29200 Brest, France
}

Correspondence to: I. Bashmachnikov (igorb@fc.ul.pt)

Received: 9 June 2012 - Published in Ocean Sci. Discuss.: 20 July 2012

Revised: 20 September 2012 - Accepted: 30 September 2012 - Published: 1 November 2012

\begin{abstract}
Meddies, intra-thermocline eddies of Mediterranean water, can often be detected at the sea surface as positive sea-level anomalies. Here we study the surface signature of several meddies tracked with RAFOS floats and AVISO altimetry.

While pushing its way through the water column, a meddy raises isopycnals above. As a consequence of potential vorticity conservation, negative relative vorticity is generated in the upper layer. During the initial period of meddy acceleration after meddy formation or after a stagnation stage, a cyclonic signal is also generated at the sea-surface, but mostly the anticyclonic surface signal follows the meddy.

Based on geostrophy and potential vorticity balance, we present theoretical estimates of the intensity of the surface signature. It appears to be proportional to the meddy core radius and to the Coriolis parameter, and inversely proportional to the core depth and buoyancy frequency. This indicates that surface signature of a meddy may be strongly reduced by the upper ocean stratification. Using climatic distribution of the stratification intensity, we claim that the southernmost limit for detection in altimetry of small meddies (with radii on the order of $10-15 \mathrm{~km})$ should lie in the subtropics $\left(35-45^{\circ} \mathrm{N}\right)$, while large meddies (with radii of $25-30 \mathrm{~km}$ ) could be detected as far south as the northern tropics $\left(25-35^{\circ} \mathrm{N}\right)$. Those results agree with observations.
\end{abstract}

\section{Introduction}

Generated by the destabilization of the Mediterranean outflow along the Iberian Peninsula and at surrounding banks, meddies (Mediterranean Water Eddies) drift across the Northeastern Atlantic, sometimes reaching the Mid-Atlantic Ridge without major change in their dynamical properties (Richardson et al., 2000; Serra and Ambar, 2002).

Meddies, warm and salty intrathermocline eddies, are isolated from the surrounding waters by strong potential vorticity gradients and show low horizontal and vertical diffusivities (Hebert, 1988; Martin et al., 2001). For meddies, horizontal intrusions are thought to be the most probable mechanism for heat and salt exchange across their lateral boundaries, but they are not an efficient mechanism for vorticity dissipation until the late stages of the eddy disintegration (Hebert, 1988; Hebert et al., 1990). Relative vorticity decay in meddies may be due to their interaction with a background shear flow, which strips vorticity away (Legras and Dritschel, 1993; Mariotti et al., 1994), or to energy dispersion through radiation of Rossby waves (Flierl, 1984). Core properties of meddies also change when they interact with seamounts. Such interactions can range from "elastic", when the eddy only slightly changes its trajectory, to "drastic", when the eddy is split into several parts or destroyed after interaction with the seamount (Van Geffen and Davies, 2000; Richardson et al., 2000; Bashmachnikov et al., 2009b).

The propagation of meddies in the ocean may be a result of various mechanisms. The simplest such mechanism is the advection of a meddy by an ambient currents (currents at the 
depth of the meddy, or barotropic currents). But typically a more efficient process is the advection of a meddy by "beta gyres", which is the formation of an antisymmetric internal dipole circulation inside the meddy that, in turn, advects the meddy (Morel, 1995). "Beta gyres" in a meddy may be formed by planetary, baroclinic or topographic beta effects. Due to baroclinic beta effect, "beta gyres" are formed via a vertical tilt of the isopycnals above or below a meddy, which leads to vertical squeezing or stretching of the meddy, which becomes horizontally asymmetric. As a result a meddy may be advected by a baroclinic ambient current (for instance a current in a layer only above or below the meddy). For baroclinic currents, direct advection by the current may be annihilated by beta gyres associated with the mean-flow potential vorticity gradient (Vandermeirsch et al., 2001), leaving other effects to dominate. Except for advection by strong ambient currents, the resulting meddy propagation speeds are a few $\mathrm{cm} \mathrm{s}^{-1}$.

Since the pioneering work by Käse et al. (1989), several insitu surveys of meddies in the Northeastern Atlantic Ocean have shown that these eddies can have a clear signature at the sea-surface (Pingree and Le Cann, 1993a, b; Pingree, 1995; Tychensky and Carton, 1998; Paillet et al., 2002; etc.) (see Table 1). On average, the geostrophic azimuthal velocities near the sea-surface are around $70 \%$ of those of the meddy core, varying from 30 to $100 \%$ (Bashmachnikov et al., 2009a). These strong surface signals, and the stability of meddies, allow their possible tracking with altimetry (Armi et al., 1988; Stammer et al., 1991; Pingree and Le Cann, 1993b; Bower et al., 1997; Richardson et al., 2000).

Up to now, no systematic investigation of meddy surface signals, nor of background ocean conditions which can affect their intensity, has been carried out. In this paper we develop criteria to determine where meddies with given characteristics can be observed at the sea-surface.

\section{Materials and methods}

For the experimental part of this work, we used several available studies which address observations of dynamic structure of water column from meddy cores to the ocean surface (Table 1). The characteristics of the meddies, their signature at the surface and the background oceanographic conditions form the test bed of the theoretical study to follow. In addition, a joint analysis of RAFOS floats' trajectories in meddies and of AVISO altimetry data was performed to examine the variations of the surface signatures of meddies with time. To study these long-term variations, we retained only the meddies thoroughly surveyed at least once with CTD sections and followed with subsurface drifters for at least several months. Meddies Hyperion, Zoe (Tychensky and Carton, 1998; Richardson and Tychensky, 1998) and Pinball (Pingree, 1995; Richardson et al., 2000) satisfied those requirements.
For each meddy, the RAFOS float trajectories were split into rotation cycles; during each cycle, the RAFOS positions were averaged to determine the position of the meddy centre. For each cycle, the mean values of the distance between the RAFOS and the meddy centre (called here "the radius"), temperature, azimuthal velocities, and meddy propagation velocities, were estimated. If several RAFOS floats were simultaneously rotating around a meddy centre, the final results represented the average values over all these floats. The results were interpolated and smoothed with piecewise cubic Hermite interpolation polynomials over 7-day intervals, centred at the same dates as the gridded altimetry data (AVISO).

From the RAFOS float data, the relative vorticity of each meddy was computed, assuming that it had a shielded Gaussian (or Rayleigh) profile (Carton et al., 1989). This hypothesis is reasonable for the radial profile of relative vorticity $\omega_{\mathrm{m}}$, in view of previous in-situ observations (Pingree and Le Cann, 1993a; Paillet et al., 2002), but finer details of real vorticity profiles will be discussed below. The Rayleigh profile of azimuthal velocity is:

$v_{\theta}(r)=\Omega r e^{-r^{2} / 2 R_{\mathrm{vm}}^{2}}$,

and relative vorticity is expressed as:

$\omega_{\mathrm{m}}(r)=\Omega\left(2-\frac{r^{2}}{R_{\mathrm{vm}}^{2}}\right) e^{-r^{2} / 2 R_{\mathrm{vm}}^{2}}$.

Here, $R_{\mathrm{vm}}$ is the radius where the azimuthal velocity $v_{\theta}$ reaches its maximum $\left(v_{\theta \max }\right)$, and the constant $\Omega=\frac{\sqrt{e} v_{\theta \max }}{R_{\mathrm{vm}}}$. The values of $v_{\theta}$ and $r$ were derived from float data, averaged over rotation cycles, while $R_{\mathrm{vm}}$ was derived from insitu sections across the meddy. The dynamical radii of meddies $\left(R_{\mathrm{m}}\right)$ were defined as the distance at which the vorticity changed sign. For a Rayleigh profile, the two radii are related by $R_{\mathrm{m}}=\sqrt{2} R_{\mathrm{vm}}$.

Gridded AVISO altimetry sea-level elevations $(\zeta)$ with a spatial resolution of about $30 \mathrm{~km}$ were used to compute the sea-surface velocity and relative vorticity with the geostrophic approximation. To reduce the measurement noise, a 7-point stencil width was used for computation of the dynamic parameters, as recommended in Arbic et al. (2012). At the surface, meddy signatures were often mixed with other dynamical structures; therefore we identified meddy surface signals from local extrema of the sea-level (Isern-Fontanet et al., 2003). These extrema are given by the Laplacian of sea-level height: $\omega_{0}=\frac{g}{f} \Delta \zeta$. Note that such extrema can also represent surface eddies. Their correlation with RAFOS float positions was therefore essential.

The accuracy of the computation peak relative vorticity from AVISO data depends on the data accuracy of the altimetry missions, as well as on how far the closest altimetry track was from the centre of the structure. When a track crosses the centre of the surface signal, the along-track sea-level anomalies (SLA) are obtained with spatial resolution of 6-7 km and 
Table 1. Characteristics of surface signatures of various meddies, derived from in-situ observations; $v_{\mathrm{m}}\left(\omega_{\mathrm{m}}\right)$ and $v_{0}\left(\omega_{0}\right)$ are the maximum azimuthal velocity (vorticity) in the meddy core and in its surface signal, respectively.

\begin{tabular}{|c|c|c|c|c|c|c|c|c|}
\hline $\begin{array}{l}\text { Meddie's name, } \\
\text { position, time and } \\
\text { min depth of } \\
\text { observations }\end{array}$ & $H, \mathrm{~m} / R_{\mathrm{vm}}, \mathrm{km}$ & $v_{\mathrm{m}}, \mathrm{cm} \mathrm{s}^{-1}$ & $v_{0}, \mathrm{~cm} \mathrm{~s}^{-1}$ & $\zeta, \mathrm{cm}$ & $\left|\omega_{\mathrm{m}}\right| / f$ & $\left|\omega_{0}\right| / f$ & $\omega_{0} / \omega_{\mathrm{m}}, \%$ & $\begin{array}{l}\text { Reference, } \\
\text { Instrumentation* }\end{array}$ \\
\hline $\begin{array}{l}\text { Ceres, } 36^{\circ} \mathrm{N}, \\
24^{\circ} \mathrm{W}, 07-09.93, \\
0 \mathrm{~m}\end{array}$ & $1000 / 30$ & 12 & 23 & 13 & 0.13 & 0.12 & $96 \%$ & $\begin{array}{l}\text { Tychensky and } \\
\text { Carton, 1998; } \\
\text { CTD, XBT, SF, } \\
\text { SLA; (south of the } \\
\text { Azores) }\end{array}$ \\
\hline $\begin{array}{l}\text { Encelade, } 33^{\circ} \mathrm{N}, \\
21^{\circ} \mathrm{W}, 10-11.93, \\
0 \mathrm{~m}\end{array}$ & $1000 / 35$ & 14 & 8 & 5 & 0.13 & 0.04 & $29 \%$ & $\begin{array}{l}\text { Tychensky and } \\
\text { Carton, 1998; CTD, } \\
\text { XBT, SF, } \\
\text { SLA; (south of the } \\
\text { Azores) }\end{array}$ \\
\hline $\begin{array}{l}\text { Hyperion, } 35^{\circ} \mathrm{N}, \\
28^{\circ} \mathrm{W}, 07.93,0 \mathrm{~m}\end{array}$ & $900 / 35$ & 20 & 13 & 8 & 0.18 & 0.06 & $33 \%$ & $\begin{array}{l}\text { Tychensky and } \\
\text { Carton, 1998; } \\
\text { CTD, XBT, SF, } \\
\text { SLA; (south of the } \\
\text { Azores) }\end{array}$ \\
\hline $\begin{array}{l}\text { Ulla, } 45^{\circ} \mathrm{N}, \\
12^{\circ} \mathrm{W}, 04.97,0 \mathrm{~m}\end{array}$ & $1100 / 15$ & 18 & 8 & 2 & 0.38 & 0.08 & $22 \%$ & $\begin{array}{l}\text { Paillet et al., } \\
\text { 2002, CTD, XBT, } \\
\text { LADCP, RAFOS, } \\
\text { DDB, SF }\end{array}$ \\
\hline $\begin{array}{l}\text { Pinball (A3), } \\
01.94,37-38^{\circ} \mathrm{N}, \\
10-12^{\circ} \mathrm{W}, 0 \mathrm{~m}\end{array}$ & $\begin{array}{r}1000(700-1200) / \\
20(10-35)\end{array}$ & $\begin{array}{r}25 \\
(20-30)\end{array}$ & $\begin{array}{r}15 \\
(10-20)\end{array}$ & 6 & 0.39 & 0.12 & $30 \%$ & $\begin{array}{l}\text { Pingree, 1995; } \\
\text { Oliveira et al., } \\
\text { 2000; RAFOS, SF, } \\
\text { SLA, SST }\end{array}$ \\
\hline $\begin{array}{l}\text { Bobby } 92,35^{\circ} \mathrm{N}, \\
23^{\circ} \mathrm{W}, 03.92,0 \mathrm{~m}\end{array}$ & $1100 / 22$ & 30 & 15 & 6 & 0.43 & 0.11 & $25 \%$ & $\begin{array}{l}\text { Pingree and Le } \\
\text { Cann, 1993b; CTD, } \\
\text { ADCP, buoys }\end{array}$ \\
\hline $\begin{array}{l}\mathrm{B} 2,38^{\circ} \mathrm{N}, 13^{\circ} \mathrm{W} \\
04-05.91,100 \mathrm{~m}\end{array}$ & $1300 / 25$ & 31 & 18 & 8 & 0.39 & 0.11 & $29 \%$ & $\begin{array}{l}\text { Schultz Tokos et } \\
\text { al., 1994; CTD, } \\
\text { RAFOS, SF }\end{array}$ \\
\hline $\begin{array}{l}\text { Aska (B1), } 38^{\circ} \mathrm{N}, \\
13^{\circ} \mathrm{W}, 04-05.91, \\
100 \mathrm{~m}\end{array}$ & $1000 / 18$ & 27 & 15 & 5 & 0.47 & 0.13 & $28 \%$ & $\begin{array}{l}\text { Schultz Tokos et } \\
\text { al., 1994; CTD, } \\
\text { RAFOS, SF }\end{array}$ \\
\hline $\begin{array}{l}\text { Smeddy, } 36^{\circ} \mathrm{N}, \\
9^{\circ} \mathrm{W}, 03.92,0 \mathrm{~m}\end{array}$ & $700 / 12$ & 20 & 8 & 2 & 0.52 & 0.10 & $20 \%$ & $\begin{array}{l}\text { Pingree and Le } \\
\text { Cann, 1993a; CTD, } \\
\text { XBT, PF, SST }\end{array}$ \\
\hline AVERAGE & & & & 5 & 0.35 & 0.10 & $30 \%$ & \\
\hline
\end{tabular}

* Instrumentation, showing deep and/or surface signatures: CTD- conductivity-temperature-depth profilers, XBT - expendable bathythermograph profilers, RAFOS, PF and DDB deep floats (free floating, profiling of deep-drogued), SF - surface floats, SLA - sea-level anomalies, SST - sea-surface temperature.

$H$ is the depth of a meddy core, $R_{\mathrm{vm}}$ is the radius of maximum azimuthal velocity, vorticity is estimated as $\omega_{\mathrm{m}}=2.8 v_{\mathrm{m}} / R_{\mathrm{vm}}$, sea-level anomaly is estimated from the quasi-geostrophic approximation: $\zeta=\left(f V_{\mathrm{S}}+V_{\mathrm{S}}^{2} / 2\right) * R_{\mathrm{m}} / g$. For the surface signal the radius is doubled in accordance with observations.

typical precision of about $2 \mathrm{~cm}$ (Chavanne and Klein, 2010), while in general the SLA error is less than $3-4 \mathrm{~cm}$ (Fu and Cazenave, 2001). To estimate the error in relative vorticity calculation, resulting from the noise in the measured SLA, a vortex with a characteristic radius of $50 \mathrm{~km}$ and a SLA drop of $5 \mathrm{~cm}$ across the radius was constructed with a grid resolution of $30 \mathrm{~km}$. At every grid-point SLA was further perturbed by a normally distributed random noise with the standard deviation changing from 1 to $1.5 \mathrm{~cm}$ and back to $1 \mathrm{~cm}$ along 5 consecutive SLA fields. This models the weekly sampling 
of a vortex moving with a speed of $3 \mathrm{~cm} \mathrm{~s}^{-1}$ from one TopexPoseidon's ground track to another. The mean peak vorticity at the eddy centre was computed and its error was estimated using Student's t-distribution. The experiment was repeated 30 times. The mean error in peak relative vorticity was about $2.5 \times 10^{-6} \mathrm{~s}^{-1}$. Since meddies often generate surface SLA of bigger radius and the SLA drop across the radius may exceed $10 \mathrm{~cm}$ (Oliveira et al., 2000), this estimate is considered to be close to the upper bound of the related error.

\section{Description of observed meddy surface signals}

Table 1 summarizes the simultaneous in-situ observations of meddies and of their surface signatures available from literature.

The peak vorticity of the meddies was computed from the Rayleigh model as $\omega_{\mathrm{m}}(0)=2 \sqrt{e} \frac{v_{\theta \max }}{R_{\mathrm{vm}}}$, where $R_{\mathrm{vm}}$ and the maximum azimuthal velocity $\left(v_{\theta \max }\right)$ are derived from observations. In fact, $\omega_{\mathrm{m}}(0)$ directly derived from the experimental distribution of $v_{\theta}$ was on average $20 \%$ smaller than that given by the Rayleigh model. The latter correction, further on applied to the results of the Rayleigh model, may be due to the fact that, close to the centre, the observed relative vorticity of meddies was most often uniform and thus did not exactly match the Rayleigh profile (see in particular, Richardson et al., 1989; Armi et al., 1989). Observations showed that $3 / 4$ of the presented meddies were coupled to a surface signature with relative vorticity $\omega_{0} \sim-0.1 f$ ( $f$ is the Coriolis parameter). The relative vorticity of the surface signal ranged from 20 to $50 \%$ (on average around $30 \%$ ) of that in the meddy core $\left(\omega_{\mathrm{m}}\right)$. Observations also indicated that the $R_{\mathrm{vm}}$ of the surface signature was twice that of the meddy.

For the meddies tracked with RAFOS floats, we fitted the meddy positions with the AVISO altimetry maps. The surface negative vorticity anomalies typically peaked above the centres of the observed meddies (i.e. less than $16 \mathrm{~km}$ away), and rarely 16 to $49 \mathrm{~km}$ away. The modulus of relative vorticity monotonically decreased to zero over the radial distances of 50 to $100 \mathrm{~km}$ (see Figs. 1-3). Nearly all selected meddies were coupled to a noticeable relative vorticity anomaly during 80 to $100 \%$ of the observation time (Table 2). The only exception was meddy Ceres, which did not show a clear surface signature for a significant part of its tracked trajectory. This meddy lost its surface signal while crossing the Azores Current and did not regain it until it got destroyed at the Irving seamount (Richardson et al., 2000).

Meddies Zoe and Hyperion possessed comparable characteristics, were observed at approximately the same latitudes and showed surface signals of similar intensity at the beginning of their registered journey. But their surface signals evolved differently.

Zoe (09.1994-02.1995) drifted westward in a dynamically calm region north of the Azores Current and generated an intense permanent surface signal along its trajectory (Fig. 1a and b). Following an initial decrease, the surface signal remained rather stable up to December-January 1995, when it sharply increased; an increase of the relative vorticity was also registered by the in-core RAFOS float (Fig. 1c). This increase was accompanied by a rapid drift of the RAFOS towards the meddy centre, suggesting strong variations in the shape of its core. The correlation of the mean and minimum relative vorticities of the surface signal with the variations in $\omega_{\mathrm{m}}$ of the meddy core (Fig. 1c), as registered by the RAFOS float, reached 0.75-0.77; this suggests a strong influence of the meddy core changes on the surface signal intensity. These strong changes may have been related to an interaction with a bottom rise of Santa Maria island, and/or to an interaction with another meddy. No in-situ data are available to identify a meddy north of Zoe, but the meddy may be connected with an anticyclonic surface signal, which was moving southwards along the eastern slope of the San Miguel-Santa Maria plateaux (Fig. 1b). A plausible eddy-eddy interaction might have taken place in November 1994, when the surface anticyclone was seen in altimetric data north of Zoe at a distance of about 2 meddy diameters. During this period Zoe sharply changed the direction of drift and began a clockwise rotation around the anticyclonic structure to the north. The abovementioned abrupt change in RAFOS characteristics occurred two months later, in January 1995, after Zoe had left the south-eastern tip of the San Miguel-Santa Maria plateaux, and might rather be a result of merging with another meddy than of topographic origin (Fig. 1a).

Meddy Hyperion (07.1993-12.1994) had a significant southward drift component. In the first year of its registered propagation, Hyperion moved from 36 to $27^{\circ} \mathrm{N}$ (Fig. 2a and b). During this period the meddy interacted with and crossed the Azores Current. After crossing the Azores Current, it underwent a long-lasting interaction with a surface cyclone detached from the jet. These two interactions were presumably responsible for the variations of the meddy surface signal during a period shorter than a month (Fig. 2c). During the initial period, the RAFOS floats in the meddy core showed a fast outward drift, in particular as the meddy interacted with the Plato seamount (Fig. 2a and c, see also Richardson and Tychensky, 1998). Later on (from November 1993 to November 1994), the RAFOS floats rotated about $30-40 \mathrm{~km}$ from the meddy centre. During this latter period, the azimuthal velocity and the core temperature showed a slight and gradual decrease with time, suggesting a continuous dissipation of the relative and potential vorticity anomalies of the meddy core (Fig. 2c). At the same time, the variations of the surface signal along the meddy track were more drastic. The mean and maximum surface signal intensity decreased substantially as the meddy rapidly drifted southward: in November 1993, in December-January 1993/1994 and in AprilJune 1994 (Fig. 2a-c). Approximated with linear trends, the modulus of the mean relative vorticity at the surface, in less than of $20 \mathrm{~km}$ away from the meddy centre, decreased by $3.0 \times 10^{-7} \mathrm{~s}^{-1}$ per month, and of its peak relative vorticity 
Table 2. Mean vorticity values (normalized by $f$ ) at various distances from the centres of meddies, as calculated from RAFOS floats; $\omega_{0}$ and $\omega_{0 \mathrm{~min}}$, are the average and the peak negative vorticity over the $100 \mathrm{~km}$ around the meddy centre.

\begin{tabular}{|c|c|c|c|c|c|}
\hline Meddy (time of observations) & $\begin{array}{r}\text { Zoe } \\
(09.94-02.95)\end{array}$ & $\begin{array}{r}\text { Hyperion } \\
(07.93-06.94)\end{array}$ & $\begin{array}{r}\text { Encelade } \\
(11.93-05.94)\end{array}$ & $\begin{array}{r}\text { Ceres } \\
(08.93-01.94)\end{array}$ & $\begin{array}{r}\text { Pinball } \\
(01-09.94)\end{array}$ \\
\hline$\omega / f$ at $20 \mathrm{~km}$ & $-0.07 \pm 0.02$ & $-0.06 \pm 0.03$ & $-0.08 \pm 0.02$ & $-0.05 \pm 0.06$ & $-0.02 \pm 0.02$ \\
\hline$\omega / f$ at $45 \mathrm{~km}$ & $-0.03 \pm 0.01$ & $-0.03 \pm 0.02$ & $-0.06 \pm 0.01$ & $-0.03 \pm 0.03$ & $-0.01 \pm 0.01$ \\
\hline$\omega / f$ at $75 \mathrm{~km}$ & $0.01 \pm 0.01$ & $-0.01 \pm 0.01$ & $-0.02 \pm 0.01$ & $-0.01 \pm 0.01$ & $-0.00 \pm 0.01$ \\
\hline $\begin{array}{l}\text { mean background } \omega / f \text { in } 4^{\circ} \times 4^{\circ} \\
\text { square }\end{array}$ & $-0.005 \pm 0.003$ & $0.001 \pm 0.005$ & $0.004 \pm 0.002$ & $0.000 \pm 0.003$ & $0.001 \pm 0.001$ \\
\hline$\omega_{0} / \omega_{\mathrm{m}}, \%$ & $20 \pm 5 \% *$ & $40 \pm 20 \%$ & $35 \pm 5 \%$ & $45 \pm 45 \%$ & $20 \pm 35 \% * *$ \\
\hline $\begin{array}{l}\omega_{0}<0, \omega_{0 \min }<0, \text { in } \% \text { of time } \\
\text { of observations }\end{array}$ & $100,100 \%$ & $93,94 \%$ & $100,100 \%$ & $70,100 \%$ & $78,100 \%$ \\
\hline $\begin{array}{l}\% \text { of time when the peak relative } \\
\text { vorticity in } 4^{\circ} \times 4^{\circ} \text { square is } \\
\text { situated over the meddy }\end{array}$ & $20 \%$ & $35 \%$ & $90 \%$ & $40 \%$ & $20 \%$ \\
\hline
\end{tabular}

* Relative vorticity of the core was set constant and equal to $-0.2 f$;

** Includes initial period of meddy stagnation, when anticyclonic signal has not been formed yet.

(not shown) - by $3.8 \times 10^{-7} \mathrm{~s}^{-1}$ per month. This is significantly faster than the decrease of the modulus of the peak relative vorticity at the meddy core $\left(2.3 \times 10^{-7} \mathrm{~s}^{-1}\right.$ per month).

Meddy Pinball (01-09.1994) was first detected shortly after its formation near the Iberian coast (Pingree, 1995). Later on, it propagated westward, merged with another meddy and finally got destroyed at the Josephine seamount (Fig. 3a). At the time of its formation, this meddy was first overlain by a surface cyclone, the formation of which concurred with the formation of the meddy. As the meddy started moving away from the continental slope in January 1994 the cyclonic signal intensified, but did not follow the meddy (Fig. 3b). About a month later, the meddy interacted with the cyclone (Richardson et al., 2000), dived under it and lost its weak anticyclonic surface signal. Finally, in April, the meddy started its travel north and then west, gaining a permanent, though weak, anticyclonic signature at the surface. The signal doubled its mean and peak surface vorticity as Pinball merged with another meddy (Richardson et al., 2000) in May-June 1994 (Fig. 3c).

\section{Theoretical estimates of meddy surface signatures}

\subsection{Homogeneous upper layer}

Observations indicate that a drifting meddy, while pushing its way through the water column, raises isopycnals above it (Hebert, 1988; Paillet et al., 2002; Carton et al., 2002). As a consequence of potential vorticity $(q)$ conservation, $q=$ $\frac{f+\omega_{0}}{\tilde{H}-H_{\mathrm{m}}}$, negative vorticity should be generated in the upper layer, above the front slope of the meddy (Paillet et al., 2002, Bashmachnikov et al., 2009a):

$\omega_{0}=-\frac{\Delta H}{\tilde{H}} f$
Here $\tilde{H}$ is the mean thickness of the upper layer and $H_{\mathrm{m}}$ is its perturbation by the moving meddy, with maximum value $\Delta H$ over the meddy centre (Fig. 4 ). $\tilde{H}$ is typically $200 \mathrm{~m}$ less than $H$, the depth of the centre of meddy core (Hebert, 1988; Paillet et al., 2002; Carton et al., 2002). Further vortex-vortex interaction may lead to alignment of the two vortices or co-rotation of the structures around a common centre (Polvani, 1991). When the radii of the vortices are smaller than or equal to the first Rossby deformation radius and when the initial separation of the centres is about half the meddy radius, the second evolution is the most probable one. Co-rotation does not result in any significant change in the parameters of the vortices (except for their relative position), and we may consider the characteristics of the meddy surface signal to remain as in the final stage of its formation process.

Taking characteristic values of $\tilde{H} \sim 700 \mathrm{~m}$ and isopycnal elevations $\Delta H \sim 50-100 \mathrm{~m}$, the vorticity, generated in the upper layer, will be $\omega_{0} \sim-0.07$ to $-0.14 f$. This represents 20 to $40 \%$ of a meddy peak vorticity (of about $-0.3 f$ ) and corresponds well to the observations in Table 1 . With $f \sim 8 \times 10^{-5} \mathrm{~s}^{-1}$, and a dynamic radius of the surface signature $R \sim 50 \mathrm{~km}$ (Table 2, see also Oliveira et al., 2000; Paillet et al., 2002), the maximum azimuthal velocity at the sea-surface is then $v_{\theta} \sim \frac{\omega_{0} R}{4} \sim 7-15 \mathrm{~cm} \mathrm{~s}^{-1}$ (compare with Figs. 1-2b).

Dynamically, a moving meddy forces the fluid above its frontal slope to diverge, but the Coriolis acceleration resists the process deflecting the fluid particles from the radial direction. As a result the vertical velocity and the sea-surface doming are induced to form the meddy surface signal in geostrophic balance. For a homogeneous upper layer and the geostrophic approximation, the sea-level anomaly (SLA) over the meddy can be estimated as:

$\zeta \sim-\frac{f R^{2} \omega_{0}}{4 g} \sim \frac{f^{2} R^{2} \Delta H}{4 g \tilde{H}}$, 

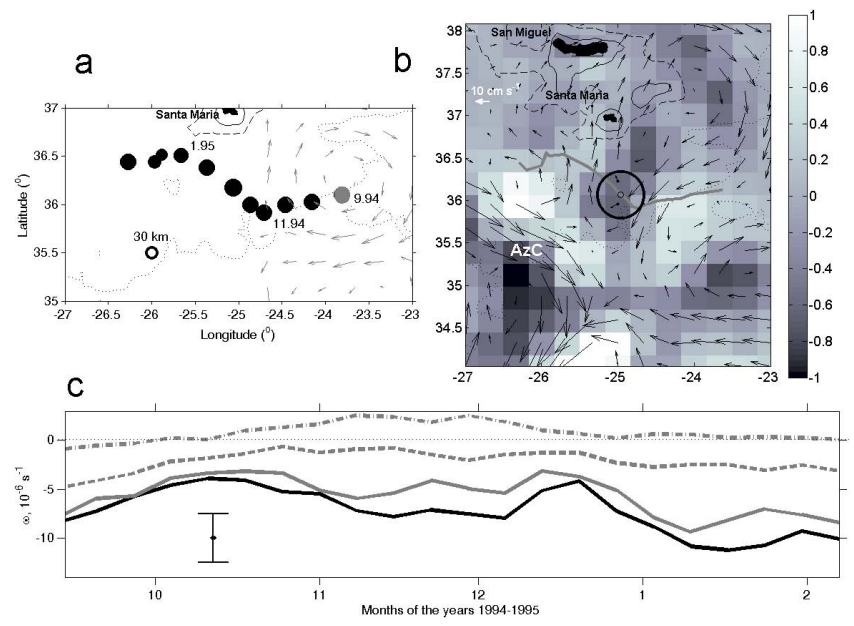

Fig. 1. Temporal evolution of the characteristics of meddy Zoe and of its surface signature. (a) Track of Zoe with month-year marked (the direction of meddy movement is to west). The width of the filled-in circles represents the RAFOS float rotation radius in $\mathrm{km}$. Typical distribution of surface geostrophic currents $\left(\mathrm{cm} \mathrm{s}^{-1}\right)$ over the meddy is presented with grey arrows (AVISO altimetry data-set). The corresponding position of the meddy is marked with the grey filled-in circle. Black lines mark depth contours: $1000 \mathrm{~m}$ (solid), $2000 \mathrm{~m}$ (dashed), $4000 \mathrm{~m}$ (dotted). (b) Example of surface vorticity field $\left(10^{-5} \mathrm{~s}^{-1}\right.$, colour) and geostrophic currents $\left(\mathrm{cm} \mathrm{s}^{-1}\right)$ derived from AVISO altimetry with the meddy position marked with a black ring at 22.11.1994. The grey line is the track of meddy centre: the meddy moved from the right (13.09.1994) to the left (10.02.1995) of the plot. (c) Time evolution of meddy peak relative vorticity (solid black line, $10^{-6} \mathrm{~s}^{-1}$ ), of the mean relative vorticity of the meddy surface signal at $r<20 \mathrm{~km}$ (solid thin grey line, $10^{-6} \mathrm{~s}^{-1}$ ), at $r \sim 20-60 \mathrm{~km}$ (dashed thin grey line, $10^{-6} \mathrm{~s}^{-1}$ ), at $r \sim 60-80 \mathrm{~km}$ (dash-dotted thin grey line, $10^{-6} \mathrm{~s}^{-1}$ ). The SLH are derived from AVISO altimetry. The vertical segments show twice the maximum error of peak relative vorticity (see Sect. 2).

where $g$ is gravity acceleration. For our set of parameters $(\Delta H \sim 50-100 \mathrm{~m}, \tilde{H} \sim 700 \mathrm{~m}), \zeta=3-6 \mathrm{~cm}$ with $R \sim 50 \mathrm{~km}$, and $\zeta=6-12 \mathrm{~cm}$ with $R \sim 70 \mathrm{~km}$. These estimates agree with the elevations observed over some meddies (Oliveira et al., 2000) and are above the altimetric measurement error, which is less than 3-4 cm (Fu and Cazenave, 2001).

Vorticity considerations also suggest that at the beginning of meddy propagation (with the upper layer fluid at rest), a cyclonic signal should form on the lee side of the meddy. Observations of meddy Pinball give evidence that at this stage, the cyclonic signal may dominate the anticyclonic surface signature (Fig. 3b). This dominance can also be explained by potential vorticity conservation. When the meddy starts propagating, the water column in front of the meddy has initially $q_{0}=\frac{f}{\tilde{H}}$, which becomes $\frac{\omega_{\mathrm{ac}}+f}{\tilde{H}-\Delta H}$ when it climbs over the meddy ( $\omega_{\mathrm{ac}}$ is the generated anticyclonic vorticity). The water column initially above the meddy has $q_{1}=\frac{f}{\tilde{H}-\Delta H}$, which becomes $\frac{\omega_{\mathrm{c}}+f}{\tilde{H}}$ as the column descends the lee side. Thus, the

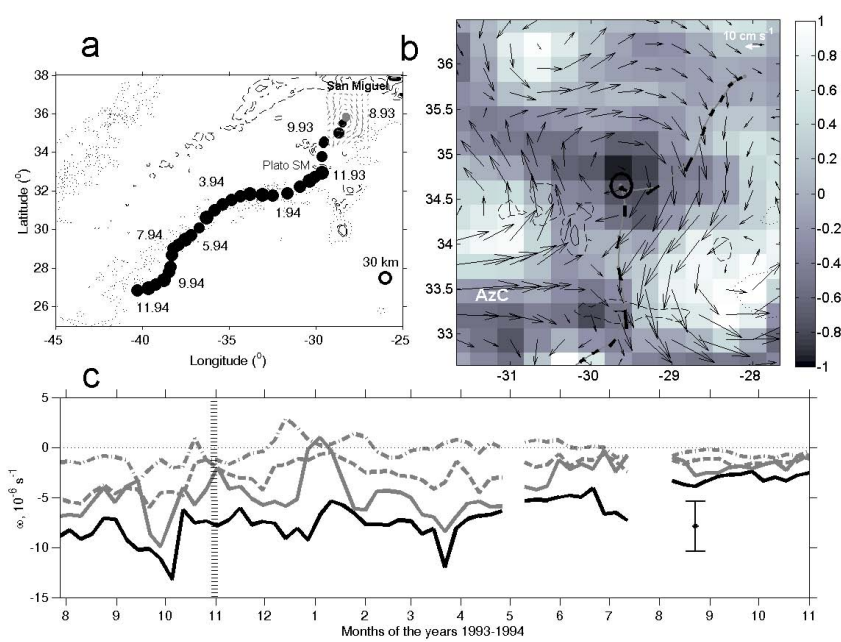

Fig. 2. Same as Fig. 1, but for meddy Hyperion (the direction of meddy movement is to southwest); (b) shows the AVISO derived geostrophic currents on 22.09.1993.

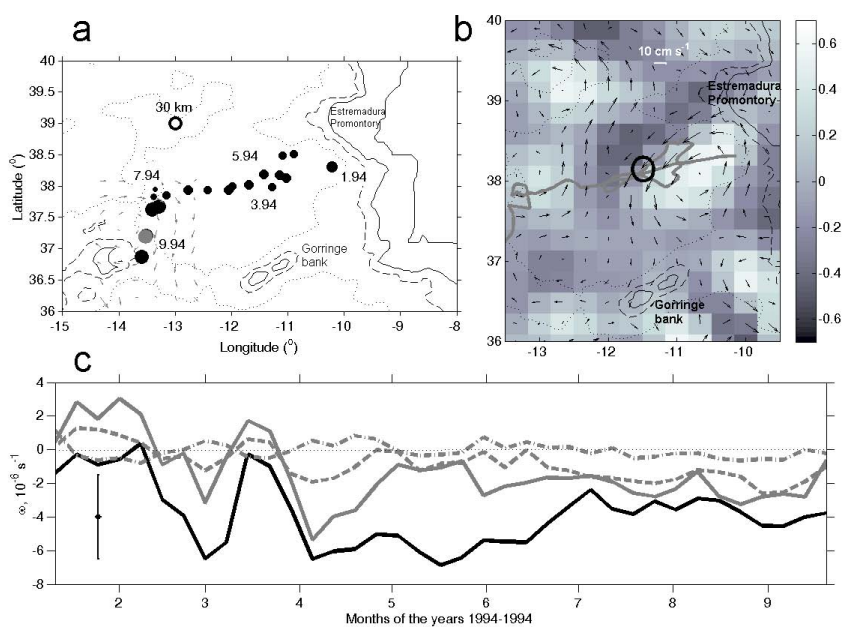

Fig. 3. Same as Fig. 1, but for the meddy Pinball (the direction of meddy movement is to west and then to south); (b) shows the AVISO derived geostrophic currents on 04.05.1994.

generated anticyclonic relative vorticity, $\omega_{\mathrm{ac}}=\frac{f \Delta H}{\tilde{H}}$, should be less than that of the cyclonic signal $\omega_{\mathrm{c}}=\frac{f \Delta H}{\tilde{H}-\Delta H}$. On the contrary, a steadily moving meddy generates only an anticyclonic surface signal, since the isopycnals above, after being pushed upward by the passing meddy, return to their initial depth levels of the upper layer at rest. 


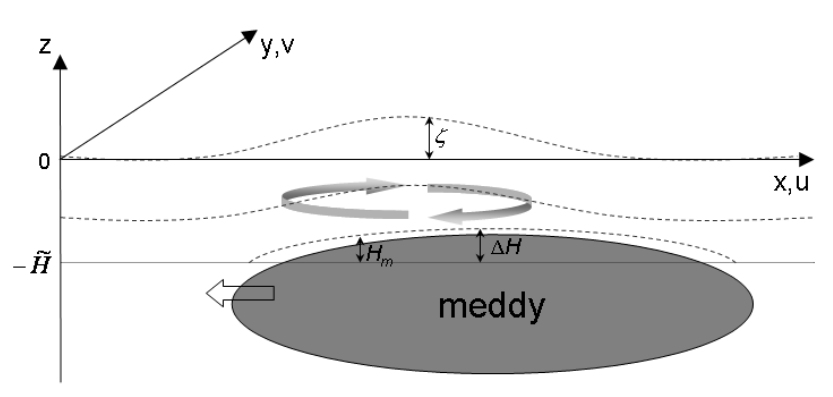

Fig. 4. Schematic view of generation of a surface signal by a meddy.

\subsection{Stratified upper layer}

Meddies propagate in the lower part of the permanent thermocline, and the layer above them is not vertically homogeneous. In the stratified case, contrary to the homogeneous case, the potential vorticity change in the upper layer is not only a function of the relative position of two isopycnic surfaces forming the layer boundaries, but also of the mean buoyancy frequency $\left(N^{2}=-\frac{g}{\bar{\rho}} \frac{\partial \rho}{\partial z}\right)$ of the layer: $q=$ $-\frac{N^{2}}{g}(f+\omega)$. When the decrease in upper layer thickness is largely compensated by an increase of $N$, little or no sealevel rise is observed. Dynamically, the acceleration of the divergent motion above the meddy due to Coriolis force is balanced by the baroclinic radial pressure gradient inside the water column.

On the one hand, the same order of magnitude of the estimate (Eq. 1) and of the observations in Table 1 suggests that the surface signals of strong meddies are only moderately damped by stratification, at least in subtropical latitudes. On the other hand, the rapid decrease of the surface signal of meddy Hyperion as it moved south (Sect. 3) showed that increasing stratification plays an important role in the surface signal damping.

We study the case when the surface signal has already formed over a meddy. Under these conditions, an area where particles are trapped exists above a meddy (Flierl, 1981). Using the quasi-geostrophic approximation with constant $f$ and $N$, the potential vorticity anomaly is

$\tilde{q}-\tilde{q}_{0}=\left(\frac{\partial^{2}}{\partial x^{2}}+\frac{\partial^{2}}{\partial y^{2}}+\frac{f^{2}}{N^{2}} \frac{\partial^{2}}{\partial z^{2}}\right) \psi$,

where $\tilde{q}_{0}$ is a constant background $\tilde{q}$ and $\psi$ is the streamfunction induced by the meddy.

The principle of the calculation to follow is that we assume that the meddy drifts steadily with respect to the upper layer, and that the upper layer has zero potential vorticity anomaly. We solve the Laplacian in three dimensions and find the streamfunction in the upper layer, driven by the meddy displacement below. The disturbance extends by $\frac{f}{N}$ times the Meddy radius. The free surface displacement is ob- tained by demanding that the pressure perturbation, thus calculated, is generated by the free surface elevation.

Indeed, negative relative vorticity is generated above a meddy to compensate the compression of the upper layer due to the meddy. The ratio of the relative vorticity terms to the stretching term is:

$\mathrm{Bu}=\frac{\nabla^{2} \psi}{\frac{f^{2}}{N^{2}} \frac{\partial^{2} \psi}{\partial z^{2}}} \sim\left(\frac{N h}{f R}\right)^{2}$.

For southern subtropical waters, $N=5 \times 10^{-3} \mathrm{~s}^{-1}, f=8 \times$ $10^{-5} \mathrm{~s}^{-1}$, and $\frac{N}{f} \sim 100$, while for northern subtropics, $N=$ $3 \times 10^{-3} \mathrm{~s}^{-1}, f=1 \times 10^{-4} \mathrm{~s}^{-1}$, and $\frac{N}{f} \sim 30$. Using the characteristics of a meddy surface signal $h=\tilde{H} \sim 700 \mathrm{~m}$, in the southern subtropics, $\tilde{q}$ over a meddy should be conserved for $R \sim 70 \mathrm{~km}$, while in the northern subtropics, $\tilde{q}$ over a meddy should be conserved for $R \sim 20 \mathrm{~km}$. Therefore, in the northern subtropics we may expect the radius of a surface signal to be close to the radius of a meddy core, while it should be sensibly larger in the southern subtropics or further south.

Taking $\tilde{q}-\tilde{q}_{0}=0$ in the layer above the meddy, and constant $\tilde{q}_{\mathrm{m}}=\tilde{q}-\tilde{q}_{0}$ inside the meddy, we get an equation for the streamfunction anomaly generated by the meddy:

$\left(\frac{\partial^{2}}{\partial x^{2}}+\frac{\partial^{2}}{\partial y^{2}}+\frac{\partial^{2}}{\partial \bar{z}^{2}}\right) \psi=\tilde{q}_{\mathrm{m}} H\left(R_{\mathrm{m}}-r\right)$,

where the rescaled vertical coordinate $\bar{z}=\frac{N}{f} z, \quad r=$ $\sqrt{x^{2}+y^{2}+\bar{z}^{2}}$ is the distance from the meddy centre, $R_{\mathrm{m}}$ is the dynamics radius of the meddy, and the Heaviside function is

$H\left(R_{\mathrm{m}}-r\right)=\left\{\begin{array}{l}1\left(r \leq R_{\mathrm{m}}\right) \\ 0\left(r>R_{\mathrm{m}}\right)\end{array}\right.$.

With the ratio of the vertical to horizontal dimensions in a meddy $\frac{\Delta H}{R_{\mathrm{m}}}=\frac{f}{N}$, the rescaling of the vertical coordinate $(z \rightarrow \bar{z})$ leads the meddy to be quasi spherical in the new coordinate system. Shifting from Cartesian to spherical coordinates $(x, y, \bar{z}) \rightarrow \boldsymbol{r}(r, \theta, \varphi)$, where $\theta$ is the polar angle counted from the horizontal XY-plane upwards, and $\varphi$ is the azimuthal angle counted clockwise from the $\mathrm{X}$-axis, the solution of the Poisson equation (Eq. 2) is (Weber and Arfken, 2004)

$$
\begin{aligned}
\psi(\boldsymbol{r}) & =-\frac{1}{4 \pi} \int_{-\frac{\pi}{2}}^{\frac{\pi}{2}} \cos \theta^{\prime} \mathrm{d} \theta^{\prime} \int_{0}^{2 \pi} \mathrm{d} \varphi^{\prime} \int_{0}^{\infty} \frac{\tilde{q}_{\mathrm{m}} H\left(R_{\mathrm{m}}-r^{\prime}\right) r^{\prime 2}}{\left|\boldsymbol{r}-\boldsymbol{r}^{\prime}\right|} \mathrm{d} r^{\prime} \\
& =-\frac{1}{4 \pi} \int_{-\frac{\pi}{2}}^{\frac{\pi}{2}} \cos \theta^{\prime} \mathrm{d} \theta^{\prime} \int_{0}^{2 \pi} \mathrm{d} \varphi^{\prime} \int_{0}^{R_{\mathrm{m}}} \frac{\tilde{q}_{\mathrm{m}} r^{\prime 2}}{\left|\boldsymbol{r}-\boldsymbol{r}^{\prime}\right|} d r^{\prime},
\end{aligned}
$$

with the definition of $r$ :

$$
\begin{aligned}
\left|\boldsymbol{r}-\boldsymbol{r}^{\prime}\right|^{2} & =\left(r^{\prime} \cos \theta^{\prime} \cos \varphi^{\prime}-r \cos \theta \cos \varphi\right)^{2}+\left(r^{\prime} \cos \theta^{\prime} \sin \varphi^{\prime}\right. \\
& -r \cos \theta \sin \varphi)^{2}+\left(r^{\prime} \sin \theta^{\prime}-r \sin \theta\right)^{2}=r^{\prime 2}+r^{2} \\
& -2 r^{\prime} r \sin \theta \sin \theta^{\prime}-2 r^{\prime} r \cos \theta \cos \theta^{\prime}\left(\cos \varphi \cos \varphi^{\prime}\right. \\
& \left.+\sin \varphi \sin \varphi^{\prime}\right) .
\end{aligned}
$$


We consider the ocean to be isotropic around the meddy centre. For an isotropic problem, we can arbitrarily define $\theta$ and $\varphi$. It is convenient to set $\theta=\frac{\pi}{2}$, for which $\left|\boldsymbol{r}-\boldsymbol{r}^{\prime}\right|=$ $\left(r^{\prime 2}+r^{2}-2 r^{\prime} r \sin \theta^{\prime}\right)^{1 / 2}$. Then Eq. (3) transforms into

$$
\begin{aligned}
\psi(\boldsymbol{r}) & =-\frac{\tilde{q}_{\mathrm{m}}}{2} \int_{-\frac{\pi}{2}}^{\frac{\pi}{2}} \int_{0}^{R_{\mathrm{m}}} \frac{\cos \theta^{\prime} r^{2}}{\left(r^{\prime 2}+r^{2}-2 r^{\prime} r \sin \theta^{\prime}\right)^{1 / 2}} \mathrm{~d} \theta^{\prime} d r^{\prime} \\
& =\frac{\tilde{q}_{\mathrm{m}}}{2} \int_{0}^{R_{\mathrm{m}}} \frac{r^{\prime}}{r}\left\{\left(r^{\prime 2}+r^{2}-2 r^{\prime} r \sin \theta^{\prime}\right)^{1 / 2}\right\}_{-\frac{\pi}{2}}^{\frac{\pi}{2}} \mathrm{~d} r^{\prime} .
\end{aligned}
$$

Since $0 \leq r^{\prime} \leq R_{\mathrm{m}} \leq r$, the expression in the curly brackets is equal to $\left(r^{\prime 2}+r^{2}-2 r^{\prime} r\right)^{1 / 2}-\left(r^{\prime 2}+r^{2}+2 r^{\prime} r\right)^{1 / 2}=$ $\left|r-r^{\prime}\right|-\left|r+r^{\prime}\right|=-2 r^{\prime}$, and Eq. (4) becomes

$\psi(\boldsymbol{r})=-\frac{\tilde{q}_{\mathrm{m}}}{r} \int_{0}^{R_{\mathrm{m}}} r^{\prime 2} \mathrm{~d} r^{\prime}=-\frac{\tilde{q}_{\mathrm{m}} R_{\mathrm{m}}^{3}}{3 r}$.

Now we consider the sea-surface to be a horizontal section of our solution at distance $z=H$ from the meddy centre ( $H$ is the depth of the meddy centre). Then we define $s=\sqrt{x^{2}+y^{2}}$ as the distance in the horizontal plane counted from the point above the meddy centre and $r=\sqrt{s^{2}+b^{2}}$, where $b=\frac{N H}{f}$. In the quasi-geostrophic approximation, the streamfunction at the sea-surface is equal to $\frac{g \zeta}{f}$, so that the sea-level elevation above a meddy can be expressed as

$\zeta(s)=\frac{f\left|\tilde{q}_{\mathrm{m}}\right| R_{\mathrm{m}}^{3}}{3 g \sqrt{s^{2}+b^{2}}}$.

The azimuthal velocity of the surface signal is

$v_{\theta}(s)=\frac{g}{f} \frac{\partial \zeta}{\partial s}=-\frac{\left|\tilde{q}_{\mathrm{m}}\right| R_{\mathrm{m}}^{3}}{3} \frac{s}{\left(s^{2}+b^{2}\right)^{3 / 2}}$,

and its relative vorticity is

$\omega(s)=\frac{\partial v_{\theta}}{\partial s}+\frac{v_{\theta}}{s}=-\frac{\left|\tilde{q}_{\mathrm{m}}\right| R_{\mathrm{m}}^{3}}{3} \frac{2 b^{2}-s^{2}}{\left(s^{2}+b^{2}\right)^{5 / 2}}$.

An example of the horizontal profiles of the sea-level elevation, azimuthal velocity and vorticity at the sea-surface, Eqs. (6)-(8), is presented in Fig. 5. From Eqs. (6)-(8), it follows that $b$ is the horizontal scale of the surface signal. In particular, the vorticity of the surface signal changes sign at $R=\sqrt{2} b$, and $v_{\theta}$ reaches its maximum at $s=b \sqrt{2}$. The dynamical characteristics of the surface signal, for a meddy with $R_{\mathrm{m}}=30 \mathrm{~km}$ with a shallow or a deep core, are given in Table 3. It follows that the deeper meddies, as well as the meddies observed further south, have larger but less intense signals.

This result raises two issues for meddy detection at the sea-surface. Firstly, the sea-level anomaly generated by a meddy should obviously be larger than the noise level of
Table 3. Characteristics of the surface signals for a meddy with the $R_{\mathrm{m}}=30 \mathrm{~km}$ and $\left|\tilde{q}_{\mathrm{m}}\right|=0.7 f$. In the northern subtropics $(40$ $\left.45^{\circ} \mathrm{N}\right) N / f=30$ and in the southern subtropics $\left(35-40^{\circ} \mathrm{N}\right) \mathrm{N} / f=$ 100.

\begin{tabular}{lrrrr}
\hline region & $\begin{array}{r}H_{\mathrm{m}}, \\
\mathrm{m}\end{array}$ & $\begin{array}{r}\zeta(0), \\
\mathrm{cm}\end{array}$ & $\begin{array}{r}\text { Radius of } \\
v_{\theta}=\max , \mathrm{km}\end{array}$ & $\begin{array}{r}\text { Radius of } \\
\omega=0, \mathrm{~km}\end{array}$ \\
\hline N subtropics & 600 & 35 & 25 & 35 \\
& 1100 & 19 & 23 & 47 \\
\hline S subtropics & 600 & 8 & 37 & 74 \\
& 1100 & 4 & 68 & 136 \\
\hline
\end{tabular}

the altimetric data. Secondly, the radius of the surface signal should be large enough to intersect at least one of the adjacent altimetric tracks (Tournadre, 1990). To the north the diameters of meddy surface signals are comparatively small. This is partly compensated by the altimetric tracks becoming closer to each other and the AVISO mesh being reduced from $29 \mathrm{~km}$ at $30^{\circ} \mathrm{N}$ to $21 \mathrm{~km}$ at $50^{\circ} \mathrm{N}$. From Eq. (6) it follows that a deep meddy with $R_{\mathrm{m}}=20-30 \mathrm{~km}$ has a SLA of $5-16 \mathrm{~cm}$ even $20 \mathrm{~km}$ away from the centre. Therefore, the surface signature of strong meddies should not be intermittent, while that of weak, small and shallow meddies may lie between altimetric tracks.

From Table 1, one can conclude that larger $\omega_{0}$ corresponds to a stronger $\omega_{\mathrm{m}}$. We also note that the $\omega_{0} / \omega_{\mathrm{m}}$ ratio follows the $R_{\mathrm{m}} / H$ ratio (Fig. 6a). From Eq. (8), the ratio of the vorticity of the surface signal to that of the meddy is

$$
\frac{\omega(0)}{\omega_{\mathrm{m}}}=\frac{2}{3}\left[\frac{\left|\tilde{q}_{\mathrm{m}}\right|}{\left|\omega_{\mathrm{m}}\right|}\right]\left(\frac{f R_{\mathrm{m}}}{N H}\right)^{3} .
$$

When $N=$ const also within the meddy core, then

$$
\begin{aligned}
\frac{\left|\tilde{q}_{\mathrm{m}}\right|}{\left|\omega_{\mathrm{m}}\right|} & =\frac{f^{2}}{\left|\omega_{\mathrm{m}}\right| N^{2}} \frac{\partial^{2} \psi}{\partial z^{2}}-1=\frac{f^{2}}{\left|\omega_{\mathrm{m}}\right| N^{2}} \frac{1}{f \bar{\rho}} \frac{\partial^{2} P}{\partial z^{2}}-1 \\
& =-\frac{g}{N^{2} \bar{\rho}} \frac{\partial \rho}{\partial z} \frac{f}{\left|\omega_{\mathrm{m}}\right|}-1=\frac{f}{\left|\omega_{\mathrm{m}}\right|}-1
\end{aligned}
$$

and the ratio is a function of the Rossby number. On another hand, the best correspondence between the values observed and predicted by Eq. (9) is obtained with fixed $\omega_{\mathrm{m}}=-0.3 f$ (Fig. 6b), rather than with $\omega_{\mathrm{m}}$ taken from Table 1. Figure $6 \mathrm{~b}$ also shows that, in compliance with observations, the ratio $\omega_{0} / \omega_{\mathrm{m}}$ predicted by Eq. (9) decreases with an increase of $\omega_{\mathrm{m}}$, but for meddies with $\left|\omega_{\mathrm{m}}\right|<0.4 f$, this ratio should be smaller than predicted by Eq. (9), and conversely for meddies with $\left|\omega_{\mathrm{m}}\right|>0.4 f$.

This may be explained by expressing Eq. (10) in another way, as the ratio of relative vorticity to stretching in a meddy: $\frac{\left|\tilde{q}_{\mathrm{m}}\right|}{\left|\omega_{\mathrm{m}}\right|}=\frac{1}{\mathrm{Bu}}-1$. Observations suggest that in older large meddies, decrease of $\left|\omega_{\mathrm{m}}\right|$ is accompanied by even stronger decrease of the stretching term (Hebert, 1988). Being initially less than unity, $B u$ grows with the meddy age, i.e. the ratio 

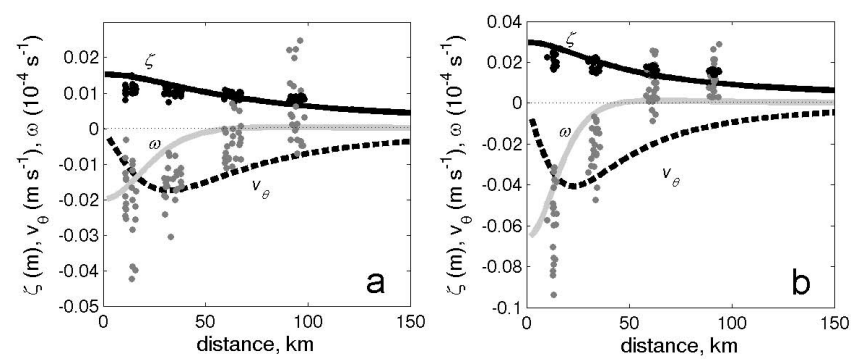

Fig. 5. Radial profiles of $\zeta$ (m, solid black line), $v_{\theta}\left(\mathrm{m} \mathrm{s}^{-1}\right.$, dash line) and $\omega\left(10^{-4} \mathrm{~s}^{-1}\right.$, solid grey line) of the surface signal of a meddy with $R_{\mathrm{m}}=35 \mathrm{~km}, H=1100 \mathrm{~m}$ and $\left|\tilde{q}_{\mathrm{m}}\right|=0.7 f$; (a) in the northern tropics $\left(f=7.3 \times 10^{-5} \mathrm{~s}^{-1}, N=3 \times 10^{-3} \mathrm{~s}^{-1}\right)$, (b) in the subtropics $\left(f=8.5 \times 10^{-5} \mathrm{~s}^{-1}, N=2.5 \times 10^{-3} \mathrm{~s}^{-1}\right)$. Observed radial profiles of $\zeta\left(\mathrm{m}\right.$, black dots) and $\omega\left(10^{-4} \mathrm{~s}^{-1}\right.$, grey dots $)$ of surface signals of meddy Hyperion (the part of the trajectory south of $32^{\circ} \mathrm{N}$ ) and meddy Zoe are overlaid on plates (a) and (b), respectively.

in Eq. (10) may decrease (not grow) for meddies with low $\left|\omega_{\mathrm{m}}\right|$. Therefore, $\frac{\left|\tilde{q}_{\mathrm{m}}\right|}{\left|\omega_{\mathrm{m}}\right|}$ may loosely depend on $\omega_{\mathrm{m}}$, and we set this ratio to be constant for all meddies, although the effect discussed is not taken into account in the calculation.

The significant difference between the observed and modelled surface signal of the meddy Ceres results from the alignment of the meddy with a surface anticyclone (Tychensky and Carton, 1998). Therefore, the surface signature of the meddy is not described by Eq. (9). The backtracking of the meddy surface signal identified this anticyclone as a detached meander of the Azores Current (Bashmachnikov et al., 2009a).

With mean $\omega_{\mathrm{m}}=-0.3 f$, the maximum value of SLA at the centre of the surface signal is

$\zeta(0)=\frac{\left|\tilde{q}_{\mathrm{m}}\right|}{3 g} \frac{f^{2} R_{\mathrm{m}}^{3}}{\mathrm{NH}} \sim 0.024 \frac{f^{3} R_{\mathrm{m}}^{3}}{\mathrm{NH}}$.

From Eq. (10), the intensity of the surface signal is most sensitive to the dynamic radius of the underlying meddy.

\section{Analysis of meddy surface signals in the Northeastern Atlantic Ocean}

The time evolution of the meddy surface signatures is now analysed taking into account our theoretical elements of the previous section (Fig. 7).

Considering slow, and mostly zonal, meddy propagations, the variation of the surface signals due to the variation of stratification should be visible over time scales of a season or longer. But at such time-scales the characteristics of a meddy core may also change. For instance, during a year of observations, the RAFOS floats trapped in Hyperion deepened by $100 \mathrm{~m}$, suggesting a corresponding increase of $H$. It is more difficult to reliably assess a decrease of the meddy radius
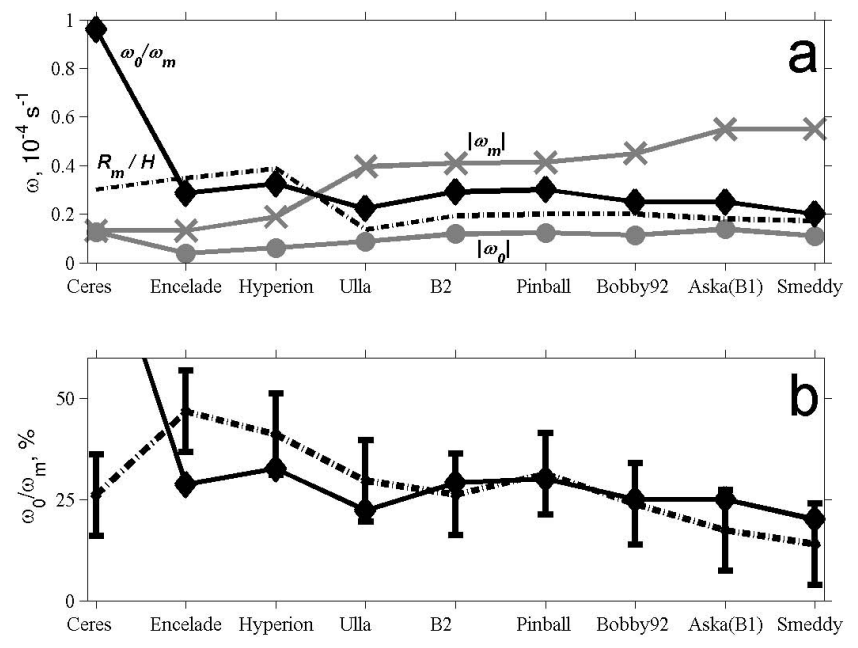

Fig. 6. (a) Variations of meddy-core peak relative vorticity $\left(\omega_{\mathrm{m}}-\right.$ thick grey line with crosses) and of surface peak relative vorticity $\left(\omega_{0}-\right.$ grey line with filled-in circles), of ratio $\omega_{0} / \omega_{\mathrm{m}}$ (solid black line with diamonds) and of ratio $R_{\mathrm{m}} / H$ (dashed black line, not in the scale). The $\mathrm{X}$-axis gives the names of the meddies listed in Table 2. (b). Observed ratio $\omega_{0} / \omega_{\mathrm{m}}$ (solid line), predicted ratio from Eq. (9) (dash-dotted black line). The error bars represent the rootmean square error, computed assuming errors in $N$ of $10 \%$, in $H$ of $100 \mathrm{~m}$ and in $R_{\mathrm{m}}$ of $3 \mathrm{~km}$. The buoyancy frequency was obtained from the climatic monthly mean density fields (WOA09).

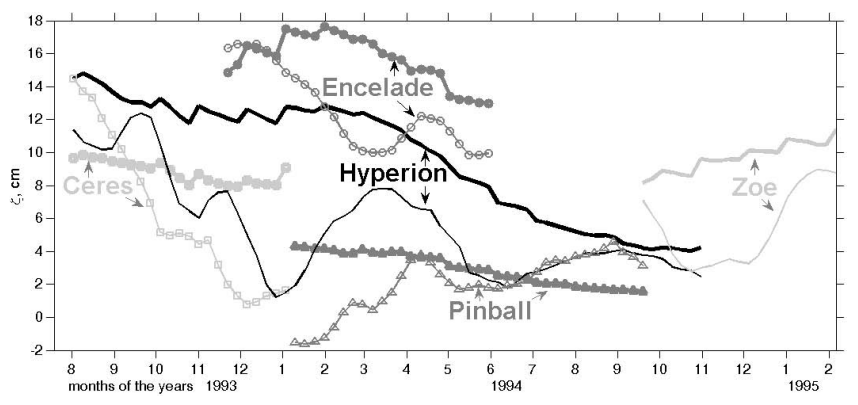

Fig. 7. Sea-level anomalies above meddies (cm) computed from AVISO altimetry (thin lines) and via expression (10) (thick lines) for meddies Hyperion (black lines), Encelade (dots and circles, dark grey lines), Pinball (triangles, dark grey lines), Ceres (squares, light grey lines) and Zoe (light grey lines). The buoyancy frequency was obtained from the climatic monthly mean density fields (WOA09).

with time (if any), since the RAFOS' positions relative to the meddy centre may be a result of their migration within the meddy. Repeated observations of meddy Sharon (Hebert et al., 1990) showed that its dynamical radius decreased by $9 \mathrm{~km}$ during a year of observations. To compute the time evolution of the meddy surface signatures in Fig. 7, we assumed that the meddy radii decreased by $5 \mathrm{~km}$ per year.

Figures 6 and 7 show that expressions (9)-(11) adequately describe the intensity and time evolution of the surface signals of meddies, though slightly overestimate the intensity of 
the sea-level anomalies over meddies with comparatively low $\omega_{\mathrm{m}}$, as has been noted earlier (cf. Fig. 6). The difference may equally result from smoothing of along-track SLA as the data are interpolated to the AVISO grid.

From November 1993 to November 1994, Hyperion moved south by six degrees of latitude. Its surface signal notably decreased (Figs. 2 and 7), a priori affected by both the decrease of meddy-core intensity and the increase of stratification. After May 1994, i.e. after the meddy crossed $30^{\circ} \mathrm{N}$, its surface signal did not exceed $5 \mathrm{~cm}$ any longer, and it became difficult to distinguish it from the background noise. The predictions correctly describe the overall trend in the intensity of the surface signal of Hyperion, although fail to explain rapid episodic drops of the signal intensity. Note that those variations happened when the meddy crossed the Azores Current (October 1993) and interacted with a cyclone (December 1993-January 1994), i.e. when the meddy surface signal is influenced by the intensive background dynamic fields.

The evolution of meddy Ceres was specific (Richardson et al., 2000) and the information on its characteristics does not allow a correct description of the variations of its surface signal. At the beginning of its study, Ceres was aligned with a surface anticyclone (Tychensky and Carton, 1998) and the SLA did not represent the meddy surface signal proper. Later on, the meddy rapidly crossed the Azores Current, an event during which the surface signal got lost (Bashmachnikov et al., 2009a). Sharp variations of the radius of rotation of RAFOS floats during this period suggest that, during this crossing, the core of this weak meddy underwent destructive changes.

Meddies Encelade and Zoe followed a zonal trajectory, which could have allowed the observation of the seasonal influence of stratification. But Encelade was trapped by the southern boundary of the Azores Current; therefore, its surface signal was also determined by this effect. The fact that Eq. (11) works reasonably well in the description of the meddy's intensity and dynamics indicates that the influence of the meddy dominated the evolution of its surface signature, compared with the influence of the meanders of the Azores Current (see also Bashmachnikov et al., 2009a, 2012). The signal over Encelade showed a $15 \%$ decrease from winter to summer.

The characteristics of meddy Zoe core are not described in the literature in sufficient detail for our analysis. Here, we used $H=1200 \mathrm{~m}, R_{\mathrm{m}}=30 \mathrm{~km}, \omega_{\mathrm{m}}=-0.20 f$ (Richardson and Tychensky, 1998). The variations of the SLA above Zoe in October-December 1995 were not related with the surface signature of the meddy itself but they were due to the influence of another anticyclone which approached Zoe from the north (see Sect. 3). The proper surface signal of Zoe during this period is better seen in the vorticity field (Fig. 1b).

Initially, the surface signal of the meddy Pinball was weaker than expected, since the meddy was in its formation stage. Its surface signal reached the estimated intensity only in April 1994, when the meddy started moving westward (Fig. 3a-b). At the end of its tracked journey, the increase in surface signal of Pinball resulted from the increase of the meddy radius and from the decrease of the meddy core depth; these two changes were due to the merger of Pinball with another meddy (with a shallower core) in June 1994 (Pingree, 1995). The surface signal then grew above the value predicted with the original characteristics of Pinball.

Meddies B2 and Aska (B1) were observed during a merging process: B1 was absorbed by the stronger meddy B2 (Schultz Tokos et al., 1994). Acceleration and deformation of the core of B1 during the merging may explain the observed deviation of the intensity of its surface signal from Eq. (11).

The gridded AVISO products allow a reliable identification of a mesoscale signal when $\zeta \geq 4 \mathrm{~cm}$ and when this signal does not entirely lie between the ground tracks of the satellites (Fu and Cazenave, 2001). For a mesoscale structure lying exactly on the ground track of an altimetric satellite, the accuracy improves to $2 \mathrm{~cm}$. Taking either one of these criteria as the critical value, we can evaluate where meddies with certain characteristics may be identified in AVISO altimetry. Based on the Figs. 6 and 7, we chose $\pm 2 \mathrm{~cm}$ error bars. The results are presented in Fig. 8. Here we should keep in mind that for large meddies (Fig. 8c and d), Eqs. (9)-(11) overestimate the meddy surface signal by approximately $2 \mathrm{~cm}$, and the northern dashed line should be taken as the reference. It follows from Fig. 8 that in the main meddy propagation path, around $36-38^{\circ} \mathrm{N}$ (Shapiro and Meschanov, 1996), meddies with dynamic radii of $20 \mathrm{~km}$ will be detectable at the surface, but their signal should be weak and fairly intermittent. Such small meddies should quickly loose their surface signatures if they take a southern path, e.g. along the coast of Africa (Hebert et al., 1990). Meddies with $R_{\mathrm{m}}=30 \mathrm{~km}$ with either shallow or deep cores are detectable in both subtropics and northern tropics, at least as far as $25-30^{\circ} \mathrm{N}$. This latter prediction corresponds well to the evolution of the surface signal of meddy Hyperion, which became weak and often intermittent south of $30^{\circ} \mathrm{N}$.

Figure 8 also shows that the isolines of the sea surface elevation $\zeta$ in the Eastern North Atlantic are nearly zonal; therefore we can easily compute critical latitudes, south of which a meddy cannot be identified in altimetry, in the $\left[H, R_{\mathrm{m}}\right]$ plane (Fig. 9). In particular, Fig. 9 shows that a meddy with $R_{\mathrm{m}}=10 \mathrm{~km}$ is not detectable in altimetric data anywhere in this region, while meddies with $R_{\mathrm{m}}=15 \mathrm{~km}$ may be episodically seen north of $35-40^{\circ} \mathrm{N}$.

\section{Conclusions}

In-situ (Table 1) and altimetric (Table 2) observations clearly indicate that most of the registered meddies showed a vertical alignment with an anticyclonic eddy at the sea surface (keeping in mind that the spatial precision allowed by the gridded AVISO altimetry products is $\pm 15 \mathrm{~km}$ ). This surface 

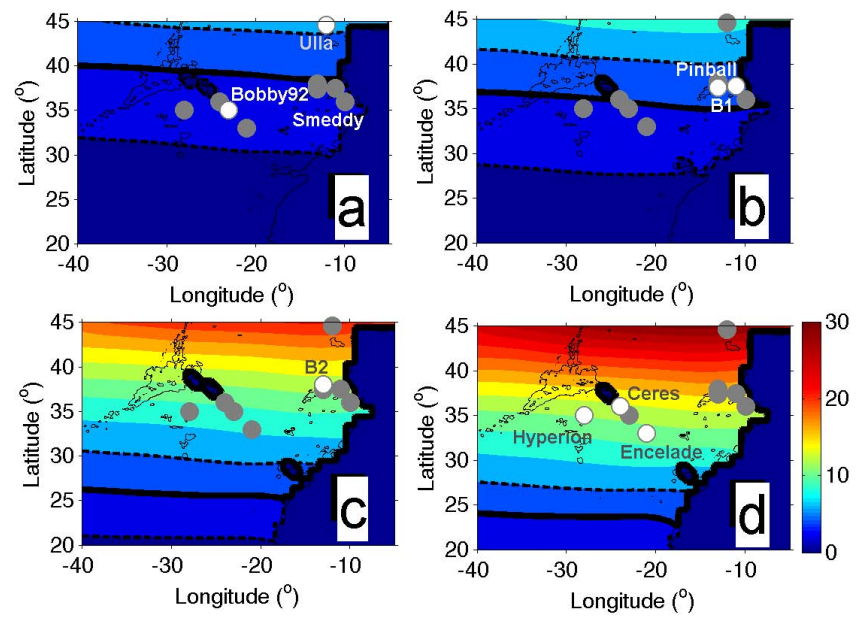

Fig. 8. Sea-level anomaly (cm): (a) $H=1100 \mathrm{~m}, R_{\mathrm{m}}=20 \mathrm{~km}$; (b) $H=800 \mathrm{~m}, R_{\mathrm{m}}=20 \mathrm{~km},\left(\right.$ c) $H=1100 \mathrm{~m}, R_{\mathrm{m}}=30 \mathrm{~km},($ d) $H=800 \mathrm{~m}, R_{\mathrm{m}}=30 \mathrm{~km}$. The thick black line marks the critical value $\zeta=4 \mathrm{~cm}$, while its position varies within the limits of the dashes lines when a $\pm 2 \mathrm{~cm}$ interval for detectable signals is introduced. The buoyancy frequency was obtained from the mean climatic density field (WOA09). Grey filled-in circles mark the meddies described in the text (Table 1); white filled-in circles are the meddies with $\left[H, R_{\mathrm{m}}\right]$ characteristics close to those presented in the respective panel.

eddy was between 50 and $100 \mathrm{~km}$ in diameter. The related sea-surface elevation and relative vorticity anomaly peaked near the meddy centre and reached 5 to $15 \mathrm{~cm}$ and -0.05 to $-0.15 f$, respectively. The surface signal of large meddies, as a rule, was sufficiently strong to be detected in altimetry, and its intensity often exceeded that of other surface anticyclonic structures in the Subtropical Northeast Atlantic. At the same time, the signal was typically smaller than that of the meanders of the Azores Current (Table 2).

Drifting meddies lift isopycnals above and in front of them and the isopycnals return to their initial position behind these meddies, thus generating anticyclonic surface vorticity anomalies. Potential vorticity conservation also suggests that when a meddy starts drifting, rapidly accelerates, or abruptly changes direction, a surface cyclone can also be generated at the lee side of a meddy. A clear cyclonic signal was formed when meddy Pinball started its westward propagation away from the coast. Near the coast the formation of the cyclonic signal may also have resulted from the interaction of meddy Pinball with a southward surface flow (Aiki and Yamagata, 2004). At the same time, the surface cyclone did not couple with the meddy surface signal as predicted by Aiki and Yamagata's model; on the contrary, it stayed in its region of formation (Richardson et al., 2000), more in accordance with the mechanism suggested here.

The surface signal of a meddy may be strongly damped by the upper ocean stratification. In a stratified ocean, the energy of this signal is partitioned between baroclinic and barotropic
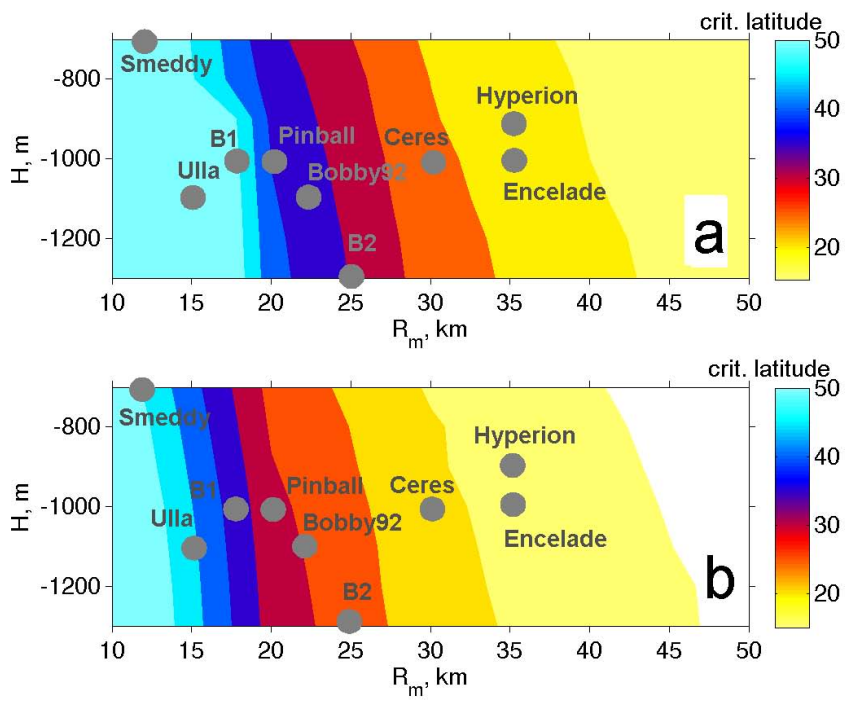

Fig. 9. Critical latitudes, presented as a function of meddy core depth $H$ and of its dynamic radius $R_{\mathrm{m}}$, for critical $\zeta$ of $4 \mathrm{~cm}$ (a) and of $2 \mathrm{~cm}$ (b). Meddies with a given set $\left[H, R_{\mathrm{m}}\right]$ of characteristics are detectable in AVISO altimetry data at latitudes north of those presented in the graph. The buoyancy frequency was obtained from the mean climatic density field (WOA09). Grey filled-in circles mark the meddies described in the text (Table 1).

components, and, in the limiting case, may not reach the surface. The vertical damping effect is mostly a function of $\frac{H}{R_{\mathrm{m}}}$. Our criteria (Eqs. 6-10) provide a fair estimate of the observed variation of surface signals above meddies. But they also slightly overestimate the intensity of the surface signals for meddies with low $\omega_{\mathrm{m}}$, while they underestimate it for high $\omega_{\mathrm{m}}$.

The background conditions enter these criteria via the $\frac{N}{f}$ ratio. This allows the calculation of sea-surface detection conditions for various meddy-core parameters. With the present accuracy of altimetric data, remote detection of meddies in subtropics is possible when the meddy cores are larger than $10-15 \mathrm{~km}$, while in tropics only very large meddies, with $R_{\mathrm{m}}$ between 25 and $35 \mathrm{~km}$, are detectable. Seasonality in the upper layer stratification affects the intensity of the signal, but the range of the seasonal variation should not exceed $2-4 \mathrm{~cm}$.

The decrease in signal intensity with time results not only from the southwestward meddy drift, but also from the variation of characteristics of meddy cores. Gradual or drastic dissipation of the cores results in decrease or loss of the signals. Conversely, meddy merger with another meddy results in an increase of the intensity of the surface signal.

A number of processes affecting the meddy signal itself were not taken into account here. Intensification of the meddy surface signal due to alignment with an existing surface anticyclone has been discussed above (meddy Ceres). Oppositely, too intensive background flow may cause the surface signal separation from the meddy, in a similar way as the 
detachment of a bottom trapped anticyclone from a seamount (Verron, 1986). This may be the reason for the sharp decrease in the intensity of the surface signals as meddies cross the Azores Current (Hyperion, Ceres). A possible loss of meddy surface signal may also be due to encompassing or blocking of the surface signal by an intensive surface structure. For example, when interacting with a surface intensified cyclone, a meddy may "dive" under it, which results in separation of the meddy surface signal and the meddy (Richardson et al., 2000; Carton et al., 2010). In these cases, the background flow field should also be considered in detail (Vandermeirsch et al., 2003a, b). When a meddy propagates with $\beta$ drift velocities, resonance with the baroclinic Rossby waves may heavily damp the surface signals. Such effects should be studied with very high resolution models of the Northeastern Atlantic Ocean.

Acknowledgements. I. B. acknowledges the contract C2008UL-CO-3 of Ciencia 2008 between Foundation for Science and Technology (FCT) and the University of Lisbon (UL) and Centre of Oceanography of the University of Lisbon. X. C. acknowledges the contract REI COMINO from DGA. The authors also acknowledge the scientific project MEDTRANS (PTDC/MAR/117265/2010) sponsored by Foundation for Science and Technology (FCT).

Edited by: A. J. George Nurser

\section{References}

Aiki, H. and Yamagata, T.: A numerical study on the successive formation of Meddy-like lenses, J. Geophys. Res., 109, C06020, doi:10.1029/2003JC001952, 2004.

Arbic, B. K., Scott, R. B., Chelton, D. B., Richman, J. G., and Shriver, J. F.: Effects of stencil width on surface ocean geostrophic velocity and vorticity estimation from gridded satellite altimeter data, J. Geophys. Res., 117, C03029, doi:10.1029/2003JC001952, 2012

Armi, L., Hebert, D., Oakey, N., Price, J. F., Richardson, P. L., Rossby, H. T., and Ruddick, B.: The history and decay of a Mediterranean salt lens, Nature, 333, 649-651, 1988.

Armi, L., Hebert, D., Oakey, N., Price, J. F., Richardson, P. L., Rossby, H. T., and Ruddick, B.: Two Years in the Life of a Mediterranean Salt Lens, J. Phys. Oceanogr., 19, 354-370, 1989.

AVISO altimeter products, produced by Ssalto/Duacs and distributed by Aviso, with support from CNES, available at: http:// www.aviso.oceanobs.com (last access: 1 November 2011), 2011.

Bashmachnikov, I., Machin, F., Mendonca, A., and Martins, A.: In-situ and remote sensing signature of meddies east of the Mid-Atlantic ridge, J. Geophys. Res., 114, C05018, doi:10.1029/2008JC005032, 2009a.

Bashmachnikov, I., Mohn, C., Pelegrí, J. L., Martins, A., Machín, F., Jose, F., and White, M.: Interaction of Mediterranean water eddies with Sedlo and Seine seamounts, Subtropical Northeast Atlantic, Deep-Sea Res. Pt. II, 56: 2593-2605, 2009 b.

Bashmachnikov, I., Boutov, D., Dias, J., Aguiar, A., and Monteiro, J. H.: Surface signature of a meddy while interacting with the Azores current, in: Geophysical Research Abstracts, Vol. 14/
EGU General Assembly, Vienna, Austria, 24-27 April 2012, EGU2012-6152-1, 2012.

Bower, A. S., Armi, L., and Ambar, I.: Lagrangian observations of meddy formation during a Mediterranean Undercurrent Seeding Experiment, J. Phys. Oceanogr., 27, 2545-2575, 1997.

Carton, X. J., Flierl, G. R., and Polvani, L. M.: The generation of tripoles from unstable axisymmetric isolated vortex structures, Europhys. Lett., 9, 339-344, 1989.

Carton, X., Cherubin, L., Paillet, J., Morel, Y., Serpette, A., and Le Cann, B.: Meddy coupling with deep cyclone in the gulf of Cadiz, J. Marine Sys., 32, 13-42, 2002.

Carton, X., Daniault, N., Alves, J., Cherubin, L., and Ambar, I.: Meddy dynamics and interaction with neighboring eddies southwest of Portugal: Observations and modelling, J. Geophys. Res., 115, C06017, doi:10.1029/2009JC005646, 2010.

Chavanne, C. P. and Klein, P.: Can oceanic submesoscale processes be observed with satellite altimetry? Geophys. Res. Lett., 37, L22602, doi:10.1029/2010GL045057, 2010.

Flierl, G. R.: Particle motions in large-amplitude wave fields, Geophys. Astro. Fluid, 18, 39-74, 1981.

Flierl, G. R.: Rossby-wave radiation from a strongly nonlinear warm eddy, J. Phys. Oceanogr., 14, 47-58, 1984.

Fu, L.-L. and Cazenave, A. (Eds.): Satellite Altimetry and Earth Sciences - A Handbook of Techniques and Applications, International Geophysics Series 69, Academic Press, London, 1-463, 2001.

Hebert, D. L.: A Mediterranean salt lens, Ph.D. thesis, Dalhousie University, Halifax, Nova Scotia, April, 187 pp., 1988.

Hebert, D., Oakey, N., and Ruddick, B.: Evolution of a Mediterranean salt lens: scalar properties, J. Phys. Oceanogr., 20, 14681483, 1990.

Isern-Fontanet, J., Garcia-Ladona, E., and Font, J.: Identification of marine eddies from altimetric maps, J. Atmos. Oceanic Technol., 20, 772-778, 2003.

Käse, R. H., Beckmann, A., and Hinrichsen, H. H.: Observational evidence of salt lens formation in the Iberian basin, J. Geophys. Res., 94, 4905-4912, 1989.

Legras, B. and Dritschel, D. G.: Vortex stripping and the generation of high vorticity gradients in two-dimensional flows, Appl. Sci. Res., 51, 445-455, 1993.

Mariotti, A., Legras, B., and Dritschel, D. G.: Vortex stripping and the erosion of coherent structures in two-dimensional flows, Phys. Fluids, 6, 3954-3962, 1994.

Martin, A. P., Richards, K. J., Law, C. S., and Liddicoat, M.: Horizontal dispersion within an anticyclonic mesoscale eddy, DeepSea Res. Pt. II, 48, 739-755, 2001.

Morel, Y.: The influence of the upper thermocline currents on intrathermocline eddies, J. Phys. Oceanogr., 25, 3247-3252, 1995.

Oliveira, P. B., Serra, N., Fiúza, A. F. G., and Ambar, I.: A study of meddies using simultaneous in-situ and satellite observations, in: Satellites, Oceanography and Society, Elsevier Oceanography Series 63, Elsevier, Amsterdam, 125-148, 2000.

Paillet, J., Le Cann, B., Carton, X., Morel, Y., and Serpette, A.: Dynamics and evolution of a northern meddy, J. Phys. Oceanogr., 32, 55-79, 2002.

Pingree, R. D.: The droguing of Meddy Pinball and seeding with ALACE floats, J. Mar. Biol. Assoc. UK, 75, 235-252, 1995.

Pingree, R. D. and Le Cann, B.: Structure of a meddy (Bobby 92) southeast of the Azores, Deep-Sea Res. Pt. I, 40, 2077-2103, 
1993a.

Pingree, R. D. and Le Cann, B.: A shallow meddy (a Smeddy) from the secondary mediterranean salinity maximum, J. Geophys. Res., 98, 20169-20185, 1993b.

Polvani, L. M.: Two-layer geostrophic vortex dynamics. Part 2. Alignment and two-layer V-states, J. Fluid Mech., 225, 241-270, 1991.

Richardson, P. L. and Tychensky, A.: Meddy trajectories in the Canary Basin measured during the Semaphore Experiment, 19931995, J. Geophys. Res., 103, 25029-25045, 1998.

Richardson, P. L., Walsh, D., Armi, L., Schröder, M., and Price, J. F.: Tracking three meddies with SOFAR floats, J. Phys. Oceanogr., 19, 371-383, 1989.

Richardson, P. L., Bower, A. S., and Zenk, W.: A census of Meddies tracked by floats, Progr. Oceanogr., 45, 209-250, 2000.

Schultz Tokos, K., Hinrichsen, H. H., and Zenk, W.: Merging and migration of two meddies, J. Phys. Oceanogr., 24, 2129-2141, 1994.

Serra, N. and Ambar, I.: Eddy generation in the Mediterranean undercurrent, Deep Sea Res. I, 49, 4225-4243, 2002.

Shapiro, G. I. and Meschanov, S. L.: Spreading pattern and mesoscale structure of Mediterranean outflow in the Iberian basin estimated from historical data, J. Mar. Sys., 7, 337-348, 1996.

Stammer, D., Hinrichsen, H. H., and Käse, R. H.: Can meddies be detected by satellite altimetry?, J. Geophys. Res., 96, 7005-7014, 1991.

Tournadre, J.: Sampling of oceanic rings by satellite radar altimiter, J. Geophys. Res., 95, 693-698, 1990.
Tychensky, A. and Carton, X.: Hydrological and dynamical characteristics of Meddies in the Azores region: a paradigm for baroclinic vortex dynamics, J. Geophys. Res., 103, 25061-25079, 1998.

Vandermeirsch, F. O., Carton, X. J., and Morel, Y. G.: Interaction between an eddy and a zonal jet, Part I. One and a half layer model, Dyn. Atmos.Oceans, 36, 247-270, 2003a.

Vandermeirsch, F. O., Carton, X. J., and Morel, Y. G.: Interaction between an eddy and a zonal jet, Part II. Two and a half layer model, Dyn. Atmos. Oceans, 36, 271-296, 2003 b.

Vandermeirsch, F., Morel, Y,. and Sutyrin, G.: Net advective effect of a vertically sheared current on a coherent vortex, J. Phys. Oceanogr., 31, 2210-2225, 2001.

Van Geffen, J. H. G. M. and Davies, P. A.: A monopolar vortex encounters an isolated topographic feature on a beta-plane, Dyn. Atmosph. Oceans, 32, 1-26, 2000.

Verron, J.: Topographic eddies in temporally varying oceanic flows, Geophys. Astrophys. Fluid Dyn., 35, 257-276, 1986.

Weber, H. J. and Arfken, G. B.: Essential mathematical methods for physicists, Elsevier, Amsterdam, 1-932, 2004.

WOA09, World Ocean Atlas 2009, available at: http://www.nodc. noaa.gov/OC5/WOA09/pubwoa09.html (last access: 1 November 2011), compiled by: Locarnini, R. A., Mishonov, A. V., Antonov, J. I., Boyer, T. P., Garcia, H. E., Baranova, O. K., Zweng, M. M., and Johnson, D. R., 2010, Volume 1: Temperature, edited by: Levitus, S., Ed. NOAA Atlas NESDIS 61, US Government Printing Office, Washington, DC, 184 pp. and Antonov, J. I., Seidov, D., Boyer, T. P., Locarnini, R. A., Mishonov, A. V., Garcia, H. E., Baranova, O. K., Zweng M. M., and Johnson, D. R., 2010. Volume 2: Salinity, edited by: Levitus, S., Ed. NOAA Atlas NESDIS 69, US Government Printing Office, Washington DC, 184, 2009. 